\title{
Differences in the hippocampal frequency of creatine inclusions between the acute and latent phases of pilocarpine model defined using synchrotron radiation-based FTIR microspectroscopy
}

\author{
J. Kutorasinska • Z. Setkowicz • K. Janeczko • C. Sandt • \\ P. Dumas • J. Chwiej
}

Received: 3 March 2013 /Revised: 12 June 2013 / Accepted: 28 June 2013 / Published online: 23 July 2013

(C) The Author(s) 2013. This article is published with open access at Springerlink.com

\begin{abstract}
Temporal lobe epilepsy (TLE) is the most common type of epilepsy in adults. Of the animal models developed to investigate the pathogenesis of TLE, the one with pilocarpineinduced seizures is most often used. After pilocarpine administration in animals, three distinct periods - acute, latent, and chronic — can be distinguished according to their behavior. The present paper is the continuation of our previous study which has shown an increased occurrence of creatine inclusions in rat hippocampal formations from the acute phase of pilocarpineinduced status epilepticus (SE) and positive correlation between their quantity and the total time of seizure activity within the observation period. In this paper, we tried to verify if anomalies in hippocampal creatine accumulation were the temporary or permanent effect of pilocarpine-evoked seizures. To realize this purpose, male Wistar rats in the latent phase (3 days after pilocarpine administration) were examined. The results obtained for the period when stabilization of animal behavior and EEG occurs were afterwards compared with ones obtained for the acute phase of pilocarpine-induced SE and for naive controls. To investigate the frequency of creatine inclusions within the hippocampal formation as well as in its selected areas (sectors 1-3 of Ammon's horn (CA1-CA3), dentate
\end{abstract}

J. Kutorasinska $(\bowtie) \cdot$ J. Chwiej

Faculty of Physics and Applied Computer Science,

AGH University of Science and Technology, 30 Mickiewicza Av., 30-059 Krakow, Poland

e-mail: Justyna.Kutorasinska@fis.agh.edu.pl

Z. Setkowicz $\cdot$ K. Janeczko

Institute of Zoology, Jagiellonian University, 24 Golebia Str.,

31-007 Krakow, Poland

C. Sandt $\cdot$ P. Dumas

SOLEIL, St Aubin BP 48 91192, Gif-sur-Yvette CEDEX, France gyrus (DG), and hilus of DG) and cellular layers (pyramidal, molecular, multiform, and granular cell layers), synchrotron radiation-based Fourier-transform infrared microspectroscopy was used. The applied technique, being a combination of light microscopy and infrared spectroscopy, allowed us to localize microscopic details in the analyzed samples and provided information concerning their chemical composition. Moreover, the use of a synchrotron source of IR radiation allowed us to carry out the research at the diffraction-limited spatial resolution which, because of the typical size of creatine inclusions (from a few to dozens of micrometers), was necessary for our study. The comparison of epileptic animals in the latent phase with controls showed statistically significant increase in the number of creatine inclusions for most of the analyzed hippocampal regions, all examined cellular layers, as well as the whole hippocampal formation. Moreover, for the hilus of the DG and CA3 area, the number of creatine deposits was higher in the latent than in the acute phase after pilocarpine injection. In light of the obtained results, an anomaly in the hippocampal accumulation of creatine is the long-term effect of pilocarpineevoked seizures, and the intensity of this phenomenon may increase with time passing from the primary injury.

Keywords Pilocarpine model of epilepsy - Creatine . SRFTIR microspectroscopy $\cdot$ Synchrotron radiation

\section{Introduction}

Epilepsy, meaning any condition with spontaneous recurrence of unprovoked seizures, is one of the most common neurological disorders. Seizures can be either generalized, when they begin simultaneously in both cerebral hemispheres, or partial, when they start at so-called epileptic foci 
and may spread to the other brain areas [1]. Epidemiological data show that temporal lobe epilepsy (TLE) is the most common type of partial seizures in adults, and the main features of TLE are localization of epileptic foci in the limbic system, a seizure-free time interval following the precipitating injury, and the presence of hippocampal sclerosis leading to reorganization of neuronal networks [2-7].

The investigations on the pathogenesis of epilepsy are rarely carried out based on the human tissues, which can be obtained only postmortem or during the surgical resection of epileptic foci. Therefore, different animal models of epileptic seizures are used. The most frequently used and highly isomorphic with human cases of TLE animal model is one with pilocarpine-induced seizures [8-10]. After pilocarpine administration in animals, the following three distinct and consecutively occurring periods can be distinguished in their behavior [11]:

1. An acute period occurring during the first $24 \mathrm{~h}$ after pilocarpine injection

2. A latent (silent) period with progressive normalization of the electroencephalography and behavior and lasting from around 4 to 44 days

3. A chronic period in which spontaneous recurrent seizures may occur

This work is the continuation of our previous research in frame of which the frequency of creatine inclusions in the hippocampal formation was examined for rats in the acute period after pilocarpine injection. The comparison of epileptic animals (6 $\mathrm{h}$ after pilocarpine administration) with controls showed then an increased accumulation of creatine deposits which were localized mainly in the dentate gyrus (DG) of the hippocampal formation and in the multiform cell layer. Furthermore, obtained data pointed to statistically significant correlation between the number of inclusions and the total time of seizure activity within the observation period [12].

The purpose of the present study was to verify if the anomalies in creatine accumulation observed $6 \mathrm{~h}$ after pilocarpine administration were only the temporary or rather long-term effect of seizures. To achieve this, the hippocampal frequency of creatine deposits in the latent phase was evaluated and compared with analogous data obtained for the acute period of pilocarpine model and for naive control animals.

Similarly as in our previous research, synchrotron radiation Fourier-transform infrared (SRFTIR) microspectroscopy was used for the detection of creatine in the nervous tissue. SRFTIR microspectroscopy is a combination of light microscopy and infrared spectroscopy. With the first method, we are able to localize microscopic details in the analyzed brain sections, while the second one provides information concerning their chemical compositions $[13,14]$. The high brightness of the synchrotron source of infrared radiation allows achieving diffraction-limited spot sizes. Because in biomedical research micrometer spatial resolution is often of great importance, SRFTIR microspectroscopy is becoming a more and more desired analytical tool in the case of investigation of different biological systems [15-19]. It concerns also the following study in frame of which creatine inclusions with the typical sizes varying from a few to dozens of micrometers were analyzed. Moreover, SRFTIR microspectroscopy is a noninvasive and nondestructive method what makes possible verification of the obtained results with the other experimental techniques such as, for example, Raman microspectroscopy, as was shown in our previous paper [12].

\section{Materials and methods}

Thin slices of hippocampal formations taken from adult male Wistar rats were used as experimental material in the present study. All animal procedures were accepted by the Bioethical Commission of the Jagiellonian University and were in agreement with the international standards. Rats were obtained from an animal colony of the Institute of Pediatrics, Collegium Medicum, Jagiellonian University, Krakow. The living environment of animals was stable and controlled: daily cycle of life was divided into 12-h-long light and 12-h-long dark phase, temperature was equal to $20 \pm 2{ }^{\circ} \mathrm{C}$, and a solid diet (Labofeed) and water were available ad libitum.

The following three groups of animals were examined in frame of the study:

$\mathrm{N}$ - six naive control animals which on the 60th day of postnatal development were perfused with physiological saline solution of high analytical purity.

$\mathrm{SE6H}$ - ten rats in the acute phase of pilocarpine-induced status epilepticus (SE). Sixty-day-old animals were intraperitoneally injected with pilocarpine $(300 \mathrm{mg} / \mathrm{kg}$, Sigma $\mathrm{P} 6503$ ) in order to induce seizures and $6 \mathrm{~h}$ later perfused with physiological saline solution.

SE72H-five animals in the latent phase which $72 \mathrm{~h}$ after pilocarpine injection were perfused with physiological saline solution.

From pilocarpine injection, animals were continuously observed during the 6-h period. Motor symptoms were rated on the six-point scale used in our previous studies [20]. Additionally, the observations provided the data on general parameters of SE such as the latency of the first motor signs (TL) and the total time of seizure activity within the observation period $(\mathrm{T})$.

After perfusion with physiological saline solution, the brains were immediately excised from the skulls and snap frozen in liquid nitrogen. No optimal cutting temperature compounds were used before cutting with a cryomicrotome. The 10- $\mu \mathrm{m}$-thick slices from the dorsal part of the hippocampal 
formation were placed on MirrIR low-e microscopic slides and stored at $-70{ }^{\circ} \mathrm{C}$ till the measurements. In order to avoid freeze-thaw damages of tissues, the temperature was increased steadily from $-70{ }^{\circ} \mathrm{C}$ to the room temperature in which we analyzed the samples. Such sample preparation allowed us to avoid the use of fixative media and paraffin having IR spectral signatures that can mask absorption bands of biological components [21].

For the detection of creatine inclusions in the nervous tissue, SRFTIR microspectroscopy was applied. The measurements were carried out at the SMIS beamline of the SOLEIL synchrotron using a Continuum XL infrared microscope with an external source of IR. The microscope equipped with a $50-\mu \mathrm{m}$ MCT detector was coupled to a FTIR ThermoNicolet spectrometer. The infrared absorption spectra were recorded in transflection mode. The double-pass aperture $10 \times 10 \mu \mathrm{m}$ was used to reduce beam size and eliminate diffraction. The $32 \times$ Schwarzchild objectives were applied to collect IR transflection spectra from discrete point maps. The spectral resolution was set to $6 \mathrm{~cm}^{-1}$, and 124 scans were averaged per background and 64 per sample spectrum. The data acquisition as well as spectral analysis was performed with OMNIC software (version 8.0). Further statistical analysis was done with the STATISTICA package (version 7.1).

\section{Results}

The main purpose of this paper was to verify if pilocarpineinduced anomalies in creatine accumulation, previously observed in the acute phase of SE, were the temporary or rather permanent effect of epileptic seizures. Therefore, to realize the goal of the study, the frequencies of hippocampal creatine deposits for the animals in the latent (SE72H) and acute (SE6H) phases after pilocarpine administration as well as for the naive controls were compared. Besides the whole hippocampal formation, a detailed study was done for particular hippocampal areas and cellular layers. For all the examined samples, the numbers of creatine inclusions were evaluated in the DG, hilus of DG $(\mathrm{H})$, and sectors $1-3$ of Ammon's horn (CA1-CA3) as well as in the pyramidal, granular, multiform, and molecular layers of hippocampal formation. The localization of the mentioned areas and cellular layers was shown in Fig. 1.

The confirmation of the presence of creatine in the hippocampal inclusions was based on the original, unprocessed spectra recorded in transflection mode. For identification purposes, the absorption bands characteristic for creatine and manifesting at the wave numbers around 1,304, 1,398, and $2,800 \mathrm{~cm}^{-1}$ were used. As one can see from Fig. 2, the 1,304and $2,800-\mathrm{cm}^{-1}$ creatine bands are almost not influenced by

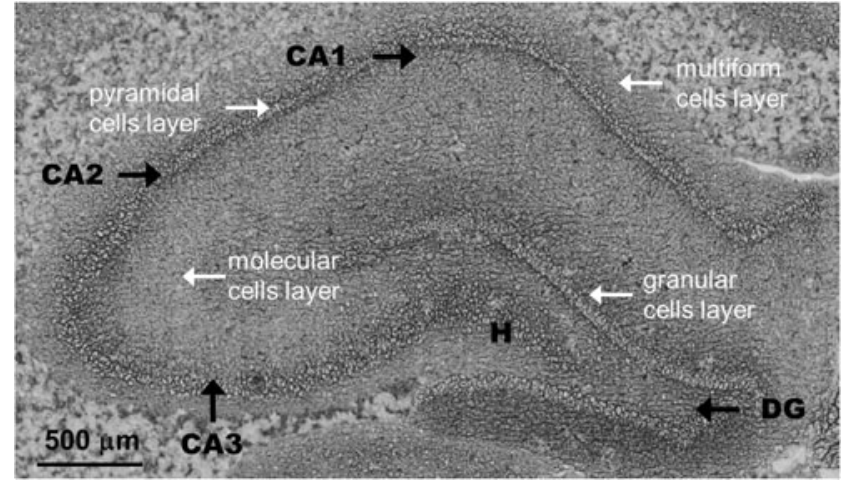

Fig. 1 The microscopic view of the rat hippocampal formation showing the areas ( $D G$ dentate gyrus, $H$ hilus of DG, $C A 1-C A 3$ sectors $1-3$ of Ammon's horn) and cellular layers selected for the detailed analysis of the frequency of creatine inclusions. Image obtained for cryomicrotome freeze-dried section with the use of a $32 \times$ optical objective of the Continuum XL microscope

the IR spectral signatures typical for hippocampal tissue. In turn, the bands at 1,304 and $1,398 \mathrm{~cm}^{-1}$ are not affected by the eventual artifacts occurring in the tissue IR spectra as a result of resonant and nonresonant Mie scattering [22].

The detailed procedure of data analysis was as follows:

1. Detection of the inclusions present in the hippocampal formations based on the detailed optical examinations of analyzed samples

2. Recording of IR absorption spectra (in transflection mode) for all the marked hippocampal inclusions

3. Confirmation of the presence of creatine based on the occurrence in the recorded spectra of the absorption bands characteristic for the compound and manifesting at the wave numbers around 2,800,1,398, and $1,304 \mathrm{~cm}^{-1}$

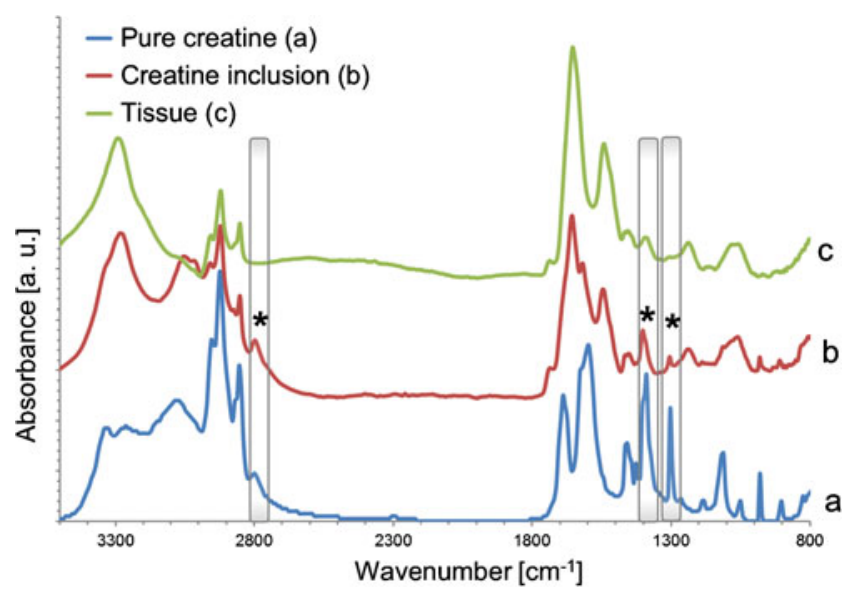

Fig. 2 The comparison of baseline corrected IR absorption spectrum recorded for creatine inclusion (b) with ones measured for pure creatine (a) and the nervous tissue (c). Absorption bands characteristic for creatine $\left(2,800,1,398\right.$, and $\left.1,304 \mathrm{~cm}^{-1}\right)$ were marked with stars 
4. Evaluation of the number of creatine-containing deposits in selected hippocampal areas and cellular layers as well as in the whole hippocampal formations

5. Verification of the existence of statistically significant differences between the analyzed animal populations using nonparametric statistical tests

In Fig. 2, the spectra recorded for the creatine-containing inclusion, pure creatine, and the nervous tissue were compared whilst in Fig. 3, the distributions of analytical creatine bands $\left(2,800,1,398\right.$, and $\left.1,304 \mathrm{~cm}^{-1}\right)$ in the DG hippocampal area from the selected animal representing the $\mathrm{SE} 72 \mathrm{H}$ group were shown.

In Tables 1 and 2, the results of quantitative analysis carried out for the three examined animal populations were presented as the mean, median, minimal, and maximal values of the number of creatine deposits in analyzed hippocampal areas and cellular layers. Additionally, the data were shown graphically as the box plots in Figs. 4 and 5.

Preliminary analysis of the data presented in Tables 1 and 2 showed increased frequency of creatine deposits in the latent comparing to the acute phase after pilocarpine administration in $\mathrm{DG}, \mathrm{H}$, and $\mathrm{CA} 3$ hippocampal areas, in all the analyzed cellular layers (pyramidal, granular, multiform, and molecular) as well as in the whole hippocampal formation. To verify statistical significance of the found relations, the nonparametric $U$ Mann-Whitney test was applied, and its results were presented in Figs. 4 and 5. Statistically significant differences $(p$ value $<0.1)$ between SE72H and $\mathrm{N}$ groups were marked with *, between SE6H and $\mathrm{N}$ group with **, and between SE72H and SE6H group with \#. The differences significant with Bonferroni-corrected $p$ value were additionally marked in red.

The differences between groups were treated as statistically significant when the $p$ value of the $U$ test was less than 0.1 . This criterion allowed us to find increased accumulation of creatine deposits for the epileptic animals in the latent phase comparing to controls in the DG ( $p$ value $=0.01), \mathrm{H}(p$ value $=0.02)$, and CA3 ( $p$ value $=0.02)$ areas; pyramidal $(p$ value $=0.02)$, granular ( $p$ value $=0.01)$, multiform ( $p$ value $=0.04)$, and molecular ( $p$ value $=0.02$ ) cellular layers as well as in the whole hippocampal formation ( $p$ value $=0.02$ ).

Comparison of the animals in the latent and acute phases after pilocarpine injection showed, moreover, higher number of creatine inclusions in $\mathrm{H}(p$ value $=0.05)$ and $\mathrm{CA} 3$ ( $p$ value $=0.08)$ areas in the phase of stabilization of animal
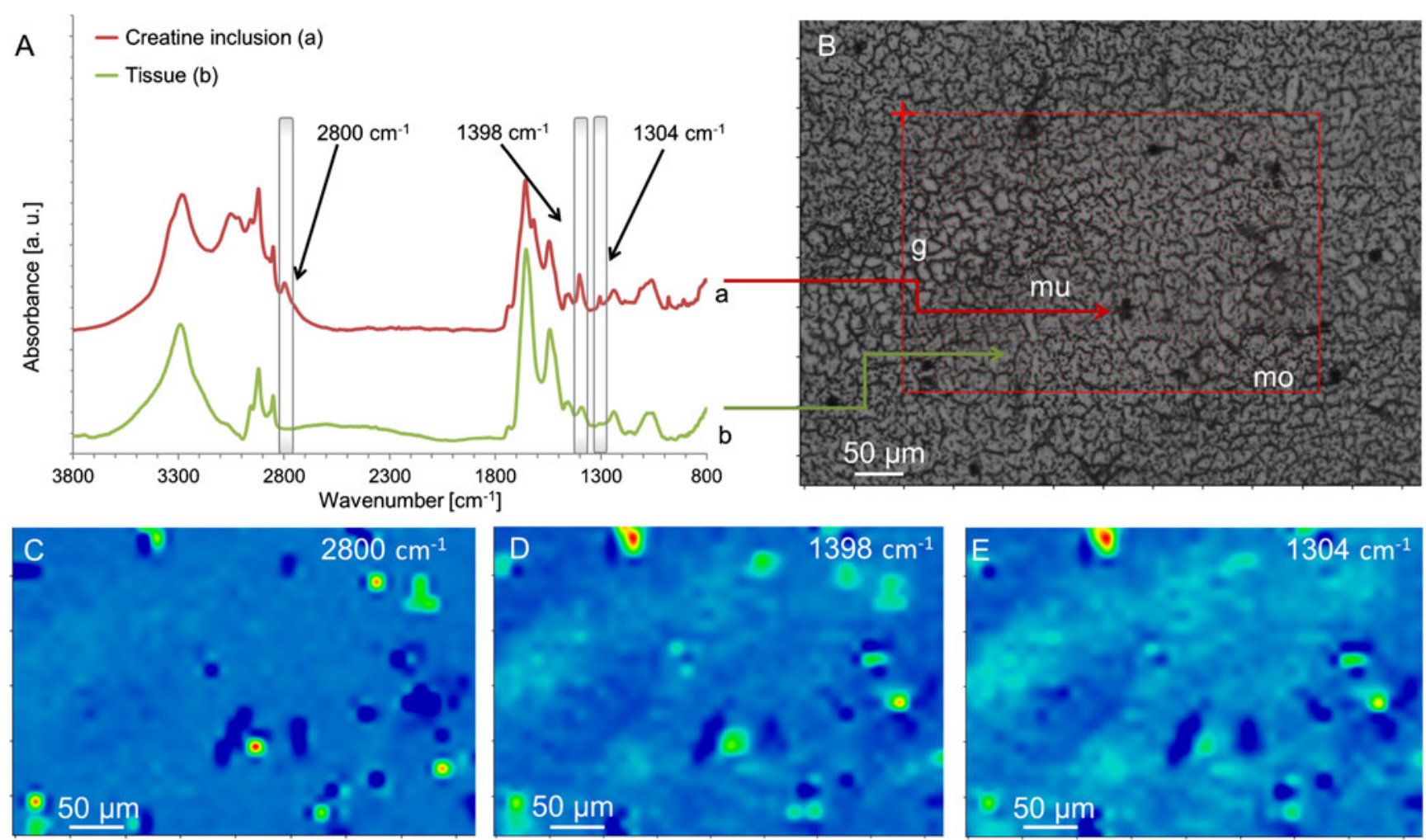

Min.

Max.

Fig. 3 The comparison of baseline corrected IR spectra recorded in selected creatine inclusion and nervous tissue (A). The microscopic view of the DG hippocampal area from the animal representing the SE72H group; creatine deposits are visible as darker points $(\mathbf{B})$. The distributions of selected creatine bands: $2,800 \mathrm{~cm}^{-1}$ (C), $1,398 \mathrm{~cm}^{-1}$ (D), and $1,304 \mathrm{~cm}^{-1}$ (E) in the rectangular tissue area visible in part (B) 
Table 1 The number of creatine inclusions in analyzed hippocampal areas

\begin{tabular}{|c|c|c|c|c|}
\hline & & $\mathrm{N}$ & SE6H & SE72H \\
\hline \multirow[t]{4}{*}{ DG } & Median & 0 & 1 & 15 \\
\hline & Min-max & $0-0$ & $0-38$ & $0-29$ \\
\hline & Mean & 0 & 10 & 16 \\
\hline & SD & 0 & 12 & 12 \\
\hline \multirow[t]{4}{*}{$\mathrm{H}$} & Median & 0 & 0 & 12 \\
\hline & Min-max & $0-1$ & $0-20$ & $0-42$ \\
\hline & Mean & 1 & 5 & 18 \\
\hline & SD & 1 & 7 & 12 \\
\hline \multirow[t]{4}{*}{ CA3 } & Median & 0 & 0 & 16 \\
\hline & Min-max & $0-4$ & $0-21$ & $0-60$ \\
\hline & Mean & 1 & 6 & 26 \\
\hline & $\mathrm{SD}$ & 2 & 7 & 23 \\
\hline \multirow[t]{4}{*}{$\mathrm{CA} 1-\mathrm{CA} 2$} & Median & 0 & 1 & 0 \\
\hline & Min-max & $0-20$ & $0-37$ & $0-22$ \\
\hline & Mean & 4 & 10 & 6 \\
\hline & SD & 6 & 12 & 7 \\
\hline \multirow[t]{4}{*}{ Total } & Median & 0 & 4 & 48 \\
\hline & Min-max & $0-25$ & $0-100$ & $0-124$ \\
\hline & Mean & 5 & 29 & 65 \\
\hline & SD & 7 & 32 & 45 \\
\hline
\end{tabular}

behavior. Although these changes were not significant with the Bonferroni-corrected $p$ value, one needs to remember that Bonferroni adjustment is an extremely conservative procedure. From one side, it protects against type I errors when multiple comparisons are being made. However, it also increases the risk of type II errors (failures to reject a false null hypothesis).

\section{Discussion}

Creatine, being a highly water-soluble molecule, can be easily removed from the tissues, and it needs to be taken into account in the sample preparation protocol. Based on our best knowledge, there is no staining protocol to detect creatine in tissues as well as no creatine antibodies enabling its
Table 2 The number of creatine inclusions in the analyzed hippocampal cellular layers

\begin{tabular}{|c|c|c|c|c|}
\hline & & $\mathrm{N}$ & SE6H & SE72H \\
\hline \multirow[t]{4}{*}{ Pyramidal layer } & Median & 0 & 1 & 9 \\
\hline & Min-max & $0-3$ & $0-26$ & $0-40$ \\
\hline & Mean & 1 & 6 & 14 \\
\hline & $\mathrm{SD}$ & 1 & 7 & 12 \\
\hline \multirow[t]{4}{*}{ Granular layer } & Median & 0 & 0 & 6 \\
\hline & Min-max & $0-0$ & $0-21$ & $0-21$ \\
\hline & Mean & 0 & 6 & 8 \\
\hline & $\mathrm{SD}$ & 0 & 7 & 7 \\
\hline \multirow[t]{4}{*}{ Multiform layer } & Median & 0 & 1 & 20 \\
\hline & Min-max & $0-17$ & $0-41$ & $0-42$ \\
\hline & Mean & 3 & 11 & 21 \\
\hline & SD & 5 & 13 & 14 \\
\hline \multirow[t]{4}{*}{ Molecular layer } & Median & 0 & 3 & 18 \\
\hline & Min-max & $0-5$ & $0-24$ & $0-50$ \\
\hline & Mean & 1 & 7 & 23 \\
\hline & $\mathrm{SD}$ & 2 & 8 & 14 \\
\hline
\end{tabular}


Fig. 4 The mean and median values of creatine inclusion quantities in the whole hippocampal formations as well as in their particular regions. Statistically significant differences $(p$ value $<0.1)$ between SE72H and $\mathrm{N}$ groups were marked with *, between SE6H and $\mathrm{N}$ groups with **, and between SE72H and SE6H groups with \#. The differences significant with Bonferronicorrected $p$ value were additionally marked in red
DG
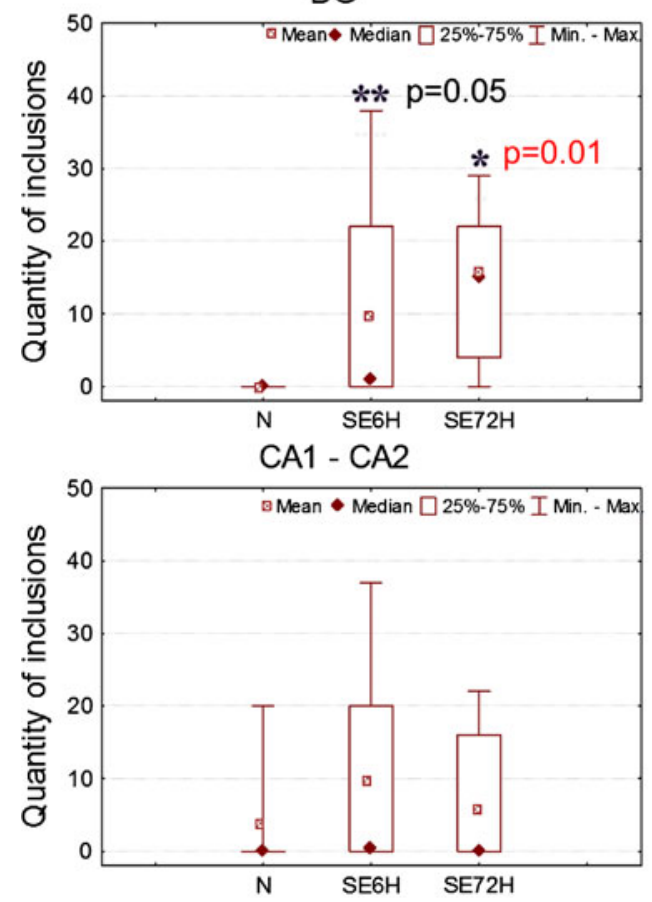

Total

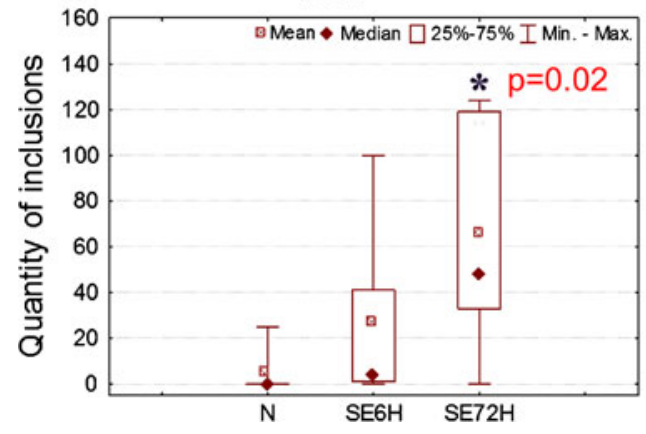

$\mathrm{H}$
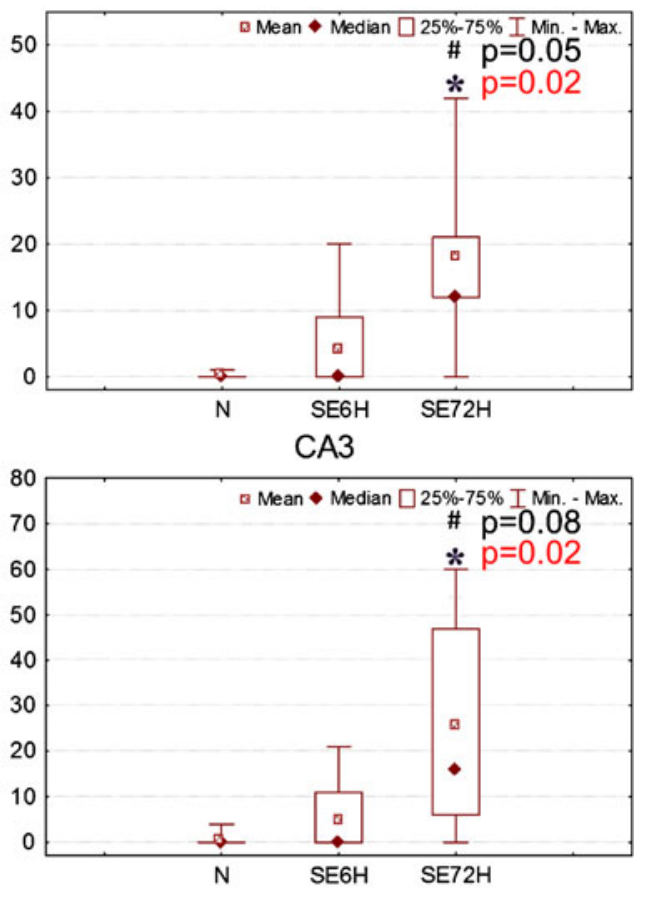

immunohistochemical analysis. Because of these reasons, physicochemical methods need to be used in order to analyze spatial distributions of creatine in tissues. One of them is SRFTIR microspectroscopy. The tissues analyzed using this method do not require the use of any stains and dyes which minimizes the risk of creatine solubilizing as well as changes in its localization during sample preparation.

The other method that can be used for spatial detection of creatine in tissue slices is Raman microspectroscopy. It was applied, as complementary to SRFTIR microspectroscopy, in our previous study as well as in research on the role of creatine in Alzheimer's disease [23]. Based on our experience, we know that, comparing to FTIR microspectroscopy, the method is much more time consuming, which makes it less useful in regular research when a large set of samples needs to be measured. The other important disadvantage of Raman microspectroscopy is its invasive character connected with the risk of local sample burning.
Time-of-flight-secondary ion mass spectrometry could be also taken into account for creatine detection in tissues; however, in the literature, one cannot find the examples of such study. Because this method probes only the surface of the sample [24-26], there is a high risk of missing some inclusions which are localized deeper in the sample.

Therefore, in the following paper, SRFTIR microspectroscopy was applied to verify if the presence of hippocampal creatine deposits in the acute phase of SE is the temporary or permanent effect of pilocarpine-evoked seizures. To realize this purpose, the animals in the latent $(\mathrm{SE} 72 \mathrm{H})$ and acute $(\mathrm{SE} 6 \mathrm{H})$ phases after pilocarpine administration were compared with the naive control animals. For all the analyzed samples, the numbers of creatine inclusions were evaluated in DG, H, CA1-CA2, and CA3 hippocampal areas; pyramidal, granular, multiform, and molecular cellular layers; as well as in the whole hippocampal formation. Statistical analysis of the obtained results was carried out 
Fig. 5 The mean and median values of creatine inclusion quantities in particular cellular layers of hippocampal formations. Statistically significant differences $(p$ value $<0.1$ ) between $\mathrm{SE72H}$ and $\mathrm{N}$ groups were marked with *, between $\mathrm{SE6H}$ and $\mathrm{N}$ groups with **, and between SE72H and SE6H groups with \#. The differences significant with Bonferroni-corrected $p$ value were additionally marked in red
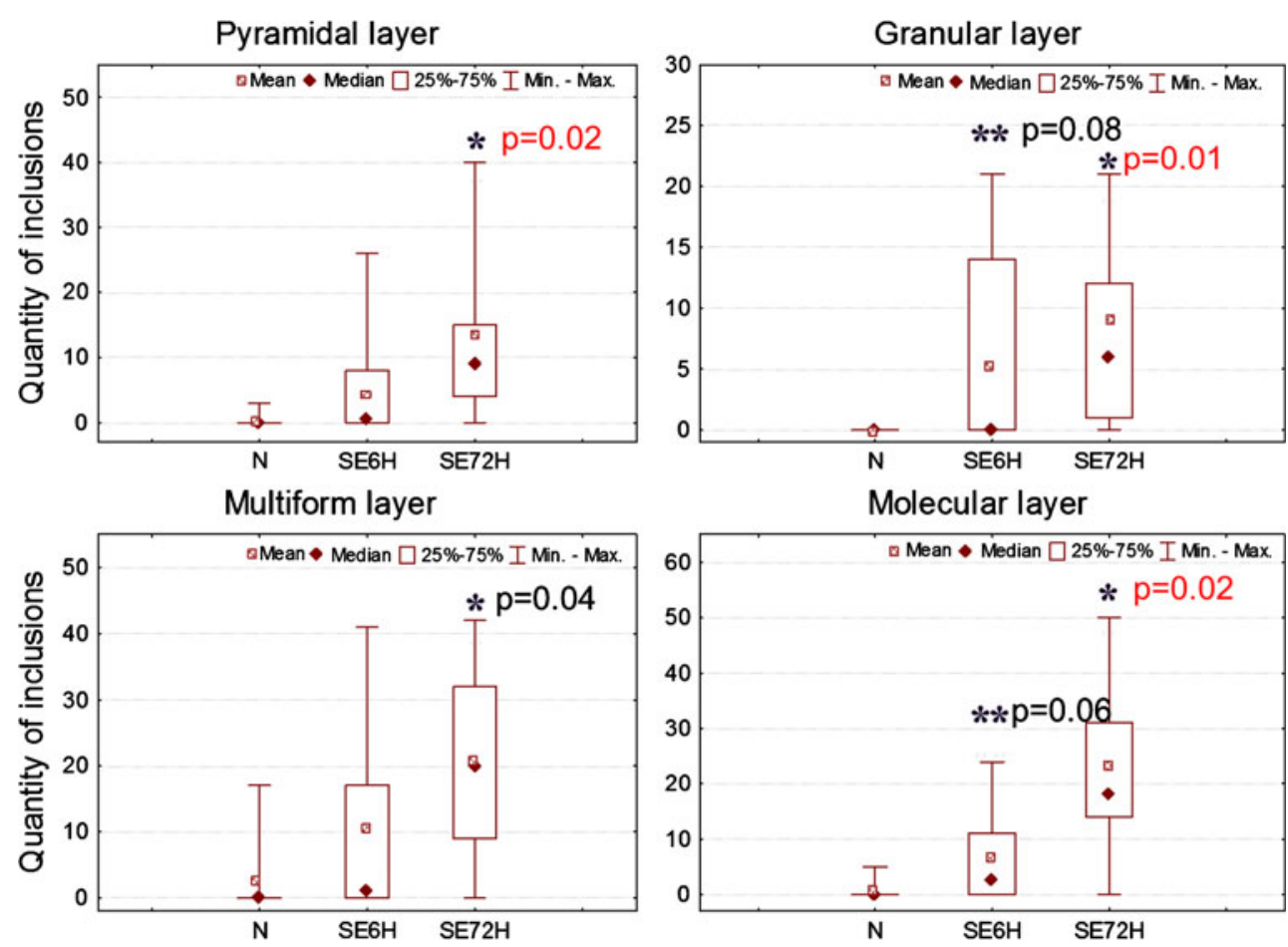

using a nonparametric $U$ Mann-Whitney test. This showed increased frequency of creatine deposits in DG, $\mathrm{H}$, and CA3 and all the examined cellular layers for the latent phase compared to the control group. It was thus confirmed that anomalies in creatine accumulation are not only the temporary effect of pilocarpine-induced seizures. Moreover, the quantity of inclusions in the latent phase was higher than in the acute phase of the pilocarpine model in the $\mathrm{H}$ and CA3 hippocampal areas.

Creatine, together with the phosphocreatine/creatine kinase system, plays an important role in cellular energy buffering and transport particularly in the tissues with high and fluctuating energy requirements such as skeletal muscles, heart, and brain [27-30]. The function of creatine in energy metabolism is connected with its interconversion to the high-energy phosphorylated analog (phosphocreatine), and this reaction is catalyzed by the enzyme creatine kinase (CK). Two CK isoforms have been identified in the brain. The first form-ubiquitous mitochondrial $\mathrm{CK}$ - converts creatine to phosphocreatine which afterwards is exported to its cytoplasmic utilization sites. The second one - cytosolic CK - uses phosphocreatine to obtain ATP from ADP in the areas of energy demand as well as converts an excessive ATP pool for energy storage [16, 31].

One of the acute high-energy demand conditions in the brain is seizure activity. Large amounts of energy necessary for seizure progression are connected with increased local glucose utilization and higher ATP turnover [32, 33]. Although ATP consumption increases during seizures, its levels in brain areas involved in seizure activity remain constant [34]. Therefore, the elevated content of creatine observed in the acute phase of pilocarpine-induced SE may just reflect the areas of increased demand for energy and the same increased replenishment of ATP from phosphocreatine. However, such a thesis does not explain the abnormal creatine accumulation observed in the latent seizure-free period. The frequency of creatine deposits in the SE72H group was not only higher comparing to controls, but in selected hippocampal areas, it exceeded the number of inclusions found for animals in the acute phase after pilocarpine administration. Such results may reflect engagement of creatine in the pathological processes occurring in the phase of behavior stabilization or be the consequence of seizure-induced changes in CK enzymatic activity.

CK activity is not uniform both in the brain as well as in the hippocampal formation which was the subject of our study. In the hippocampal formation, mitochondrial CK immunoreactivity is observed mainly in pyramidal cells from sectors $1-3$ of CA, DG granule, and hilar neurons. In turn, the cytosolic form of CK presents increased immunoreactivity in astrocytes and a small subpopulation of hilar neurons [35]. Kim et al. [23] showed that in the acute phase of pilocarpine-induced SE, hippocampal immunoreactivity of cytosolic $\mathrm{CK}$ decreases to $70 \%$ of the control level whilst for the CK mitochondrial form, it remains unaltered. For the chronic phase of the pilocarpine model, the authors obtained exactly opposite relations, and markedly decreased mitochondrial CK immunoreactivity was explained through the massive neuronal loss in CA and the hilus [22]. Therefore, the abnormal accumulation of creatine in the latent phase, which was observed in our study, may result 
from decreased enzymatic activity of one or both of the brain CK forms. Such thesis seems to be confirmed with the research of Jost et al. carried out on mice lacking the expression of the cytosolic CK isoform [36] and that of Streijger et al. in frame of which CK double knockout animals were examined [37]. Both the studies showed, for animals with decreased activity of CK, abnormalities in the formation and maintenance of hippocampal mossy fiber connections. Mice deficient in cytosolic CK had larger intra-infrapyramidal mossy fiber areas. In turn, in those lacking both $\mathrm{CK}$ isoforms, a relative increase of size of suprapyramidal and intra-infrapyramidal mossy fiber areas was observed. As it was shown in many researches, aberrant mossy fiber sprouting of granule cell axons into the molecular layer and hilus, as well as the stratum oriens in CA3 [38], may give significant input in the excessive excitability and epileptic seizures occurring both in humans and in animal models of epilepsy [39-43]. The mentioned phenomenon was also observed in our previous studies on rats from the latent phase of the pilocarpine model [44, 45]. For these animals, increased $\mathrm{Zn}$ areal density, probably from large terminals of mossy fibers of dentate granule cells, was observed in selected areas of hippocampal formation.

\section{Conclusions}

The results presented in the following paper undoubtedly confirmed the usefulness of SRFTIR microspectroscopy for the detection of creatine deposits in the nervous tissue. Comparison of the rats from the latent phase after pilocarpine administration with naive controls showed that anomalies in creatine accumulation are not only the temporary but permanent or at least long-term effect of epileptic seizures. Moreover, the number of the deposits observed in selected regions of hippocampal formation was higher for the latent than for the acute phase of pilocarpine model, and increased frequency of creatine inclusions 3 days after seizure induction is probably an effect of decreased enzymatic activity of $\mathrm{CK}$.

Acknowledgments This work was partially supported by the Polish Ministry of Science and Higher Education and its grants for scientific research 2921/B/T02/2011/40 and for the statutory scientific activity of the Institute of Zoology (Jagiellonian University). The research leading to these results has received funding from the European Community's Seventh Framework Programme (FP7/2007-2013) under grant agreement no. 312284 and was realized in frame of SOLEIL experimental grants 20090747 and 20110130. The authors wish to express their appreciation to Prof. Wojciech Luzny and Prof. Henryk Figiel for valuable discussions and comments in the preparation of the manuscript.

Open Access This article is distributed under the terms of the Creative Commons Attribution License which permits any use, distribution, and reproduction in any medium, provided the original author(s) and the source are credited.

\section{References}

1. Alarcon G, Valentin A (2012) Introduction to epilepsy. Cambridge University Press, Cambridge

2. Engel J, Pedley TA (eds) (2008) Epilepsy: a comprehensive textbook. Lippincott Williams \& Wilkins, Philadelphia

3. Curia G, Longo D, Biagini G, Jones RSG, Avoli M (2008) The pilocarpine model of temporal lobe epilepsy. J Neurosci Methods 172:143-157

4. Cendes F (2005) Progressive hippocampal and extrahippocampal atrophy in drug resistant epilepsy. Curr Opin Neurol 18:173-177

5. Bartolomei F, Khalin M, Wendling F, Sontheimer A, Regis J, Ranjeva JP (2005) Entorhinal cortex involvement in human mesial temporal lobe epilepsy: an electrophysiologic and volumetric study. Epilepsia 46:677-687

6. Mathern GW, Kuhlman PA, Mendoza D, Pretorious JK (1997) Human fascia dentate anatomy and hippocampal neuron densities differ depending on the epileptic syndrome and age at first seizure. J Neuropathol Exp Neurol 56:199-212

7. Mathern GW, Adelson PD, Cahan LD, Leite JP (2002) Hippocampal neuron damage in human epilepsy: Mayer's hypothesis revisited. Prog Brain Res 135:237-251

8. Cavalheiro EA (1995) The pilocarpine model of epilepsy. Ital J Neurol Sci 16:33-37

9. Turski L, Ikonomidou C, Turski WA, Bortolloto ZA, Cavalheiro AE (1998) Review: cholinergic mechanisms and epileptogenesis. The seizures induced by pilocarpine: a novel experimental model of intractable epilepsy. Synapse 3:154-171

10. Loscher W (2002) Animal models of epilepsy for the development of antiepileptic and disease-modifying drugs. A comparison of the pharmacology of kindling and post-status epilepticus models of temporal lobe epilepsy. Epilepsy Res 50:105-123

11. Scorza FA, Arida RM, Da Graca Naffah-Mazzacoratti M, Scerni DA, Carderazzo L, Cavalheiro EA (2009) The pilocarpine model of epilepsy: what have we learned? An Acad Ciencias 81:345-365

12. Dulinska J, Setkowicz Z, Janeczko K, Sandt C, Dumas P, Uram L, Gzielo-Jurek K, Chwiej J (2012) Synchrotron radiation Fourier-transform microspectroscopy study showed an increased frequency of creatine inclusions in the rat hippocampal formation following pilocarpine-induced seizures. Anal Bioanal Chem 402:2267-2274

13. Miller LM, Dumas P (2010) From structure to cellular mechanism with infrared microspectroscopy. Curr Opin Struct Biol 20:1-8

14. Dumas P, Sockalingum GD, Sulé-Suso J (2007) Adding synchrotron radiation to infrared microspectroscopy: what's new in biomedical applications? Trends Biotechnol 25:40-44

15. Ali K, Lu Y, Das U, Sharma RK, Wiebe S, Meguro K, Sadanand V, Fourney DR, Vitali A, Kelly M, May T, Gomez J, Pellerin E (2010) Biomolecular diagnosis of human glioblastoma multiforme using synchrotron mid-infrared spectromicroscopy. Int J Mol Med 26:1116

16. El Bedewi A, El Anany G, El Mofty M, Kretlow A, Park S, Miller LM (2010) The use of synchrotron infrared microspectroscopy in the assessment of cutaneous T-cell lymphoma vs. pityriasis lichenoides chronic. Photodermatol Photoimmunol Photomed 26:93-97

17. Le Naour F, Bralet MP, Debois D, Sandt C, Guettier C, Dumas P, Brunelle A, Laprévote O (2009) Chemical imaging on liver steatosis using synchrotron infrared and ToF-SIMS microspectroscopies. PLoS One 4:e7408

18. Leskovjan AC, Lanzirotti A, Miller LM (2009) Amyloid plaques in PSAPP mice bind less metal than plaques in human Alzheimer's disease. Neuroimage 47:1215-1220

19. Patel II, Harrison WJ, Kerns JG, Filik J, Wehbe K, Carmichael PL, Scott AD, Philpott MP, Frogley MD, Cinque G, Martin FL (2012) Isolating stem cells in the inter-follicular epidermis employing 
synchrotron radiation-based Fourier-transform infrared microspectroscopy and focal plane array imaging. Anal Bioanal Chem 404:1745-1758

20. Setkowicz Z, Kłak K, Janeczko K (2003) Long-term changes in postnatal susceptibility to pilocarpine-induced seizures in rats exposed to gamma radiation at different stages of prenatal development. Epilepsia 44:1267-1273

21. Martin FL, Kelly JG, Llabjani V, Martin-Hirsch PL, Patel II, Trevisan J, Fullwood NJ, Walsh MJ (2010) Application of infrared spectroscopy to distinguish cell types or populations based on the derivation and computation analyses of a biochemical-cell fingerprint. Nat Protoc 5:1748-1760

22. Bassan P, Sachdeva A, Kohler A, Hughes C, Henderson A, Boyle J, Shanks JH, Brown M, Clarke NW, Gardner P (2012) FTIR microscopy of biological cells and tissue: data analysis using resonant Mie scattering (RMieS) EMSC algorithm. Analyst 137:1370-1377

23. Gallant M, Rak M, Szeghalmi A, Del Bigio MR, Westaway D, Yang J, Julian R, Gough KM (2006) Focally elevated levels of creatine detected in APP transgenic mice and Alzheimer disease brain tissue. J Biol Chem 281:5-8

24. Brunelle A, Touboul D, Laprévote O (2005) Biological tissue imaging with time-of-flight secondary ion mass spectrometry and cluster ion sources. J Mass Spectrom 40:985-999

25. Brunelle A, Laprévote O (2007) Recent advances in biological tissue imaging with time-of-flight secondary ion mass spectrometry: polyatomic ion sources, sample preparation, and applications. Curr Pharm Des 13:3335-3343

26. Brunelle A, Laprévote O (2009) Lipid imaging with cluster time-offlight secondary ion mass spectrometry. Anal Bioanal Chem 393:31-35

27. Bessman SP (1985) The creatine-creatine phosphate energy shuttle. Ann Rev Biochem 54:831-862

28. Wallimann T, Wyss M, Brdiczka D, Nicolay K, Eppenberger HM (1992) Intracellular compartmentation, structure and function of creatine kinase isoenzymes in tissues with high and fluctuating energy demands: the 'phosphocreatine circuit' for cellular energy homeostasis. Biochem J 281:21-40

29. Andres RH, Ducray AD, Schlattner U, Wallimann T, Widmer HR (2008) Functions and effects of creatine in the central nervous system. Brain Res Bull 76:329-343

30. Wyss M, Kaddurah-Daouk R (2000) Creatine and creatinine metabolism. Physiol Rev 80:1107-1213

31. Schlattner U, Tokarska-Schlattner M, Wallimann T (2006) Mitochondrial creatine kinase in human health and disease. Biochim Biophys Acta 1762:164-180

32. El Hamdi G, De Vasconcelos AP, Vert P, Nehlig A (1992) An experimental model of generalized seizures for the measurement of local cerebral glucose utilization in the immature rat. I. Behavioral characterization and determination of lumped constant. Brain Res Dev Brain Res 69:233-242
33. Holtzman D, Meyers R, O'Gorman E, Khait I, Wallimann T, Allred E, Jensen F (1997) In vivo brain phosphocreatine and ATP regulation in mice fed a creatine analog. Am J Physiol 272:1567-1577

34. Folbergrová J (1997) Anticonvulsant action of both NMDA and non-NMDA receptor antagonists against seizures induced by homocysteine in immature rats. J Exp Neurol 145:442-450

35. Kim DW, Yeo SI, Ryu HJ, Kim JE, Song HK, Kwon OS, Choi SY, Kang TC (2010) Effects of creatine and $\beta$-guanidinopropionic acid and alterations in creatine transporter and creatine kinases expression in acute seizure and chronic epilepsy models. BMC Neurosci $11: 141$

36. Jost CR, Van Der Zee CE, In't Zandt HJ, Oerlemans F, Verheij M, Streijger F, Fransen J, Heerschap A, Cools AR, Wieringa B (2002) Creatine kinase B-driven energy transfer in the brain is important for habituation and spatial learning behaviour, mossy fibre field size and determination of seizure susceptibility. Eur J Neurosci 15:1692-1706

37. Streijger F, Oerlemans F, Ellenbroek BA, Jost CR, Wieringa B, Van der Zee CEEM (2005) Structural and behavioural consequences of double deficiency for creatine kinases BCK and UbCKmit. Behav Brain Res 157:219-234

38. Scharfman HE (2007) The CA3 backprojection to the dentate gyrus. Prog Brain Res 163:627-637

39. Masukawa LM, O'Connor WM, Burdette LJ, McGonigle P, Sperling MR, O'Connor MJ, Uruno K (1997) Mossy fiber reorganization and its possible physiological consequences in the dentate gyrus of epileptic humans. Adv Neurol 72:53-68

40. Isokawa M, Mello LE (1991) NMDA receptor-mediated excitability in dendritically deformed dentate granule cells in pilocarpinetreated rats. Neurosci Lett 129:69-73

41. Wuarin JP, Dudek FE (1996) Electrographic seizures and new recurrent excitatory circuits in the dentate gyrus of hippocampal slices from kainate-treated epileptic rats. J Neurosci 16:4438-4448

42. Lynch M, Sutula T (2000) Recurrent excitatory connectivity in the dentate gyrus of kindled and kainic acid-treated rats. J Neurophysiol 83:693-704

43. Dudek FE, Sutula TP (2007) Epileptogenesis in the dentate gyrus: a critical perspective. Prog Brain Res 163:755-773

44. Chwiej J, Dulinska J, Janeczko K, Appel K, Setkowicz Z (2012) Variations in elemental compositions of rat hippocampal formation between acute and latent phases of pilocarpine induced epilepsy-an X-ray fluorescence microscopy study. J Biol Inorg Chem 17:731739

45. Chwiej J, Kutorasinska J, Janeczko K, Gzielo-Jurek K, Uram L, Appel K, Simon R, Setkowicz Z (2012) Progress of elemental anomalies of hippocampal formation in the pilocarpine model of temporal lobe epilepsy-X-ray fluorescence microscopy study. Anal Bioanal Chem 404:3071-3080 